Perhaps now is the time to ask, Must all nurses be trained in hospital? There is a big field of work in the community for which long experience in major surgery or with positivepressure respirators is unnecessary. Of all the students who arrive at the hospital school expressing a desire to help people more than a third will find the physical and emotional demands of hospital life too severe and will give up. Many of these regret their inability to continue and might have much to offer in community service.

Most university students build their degree by success in course units of their choice, and the Briggs Committee might find a parallel here for attaining registration by gaining qualification in a series of different nursing courses. The student who was drawn to hospital work could spend the greater part of her training there, while the community nurse would select only the basic hospital course. The student who left before registration might later gain further qualifying units as domestic circumstances allowed. It is to be hoped that the committee will not confine itself to studying the present, or it will be overtaken by the future.

\section{Osteoporosis and Fluoride Therapy}

One striking feature of osteoporotic bone is that it can still produce callus after a fracture. If trauma can induce new bone formation then it should be possible to reproduce the effect metabolically. Fluoride, one of the possible stimuli, has different effects on bone according to the age of the subject, the rate of administration, and the length of time for which it is given. It is incorporated into mineral by a process of hydroxyl radical substitution, so that the mineral becomes more resistant to resorptive processes. ${ }^{12}$ In young bone this chemical substitution may make the mineral more resistant to the enhancement of resorption by parathyroid hormone. ${ }^{3}$ Fluoride may also be incorporated in bone as fluorocitrate, ${ }^{4}$ which is highly toxic to mitrochondrial respiration. Changes in citrate production in bone induced by feeding large amounts of fluoride in a short time led to the deposition of $0.4 \%$ fluoride in bone and a $40 \%$ reduction in the amount of bone citrate, ${ }^{5}$ though the vitamin $\mathrm{D}$ enhancement of the bone citrate production was not inhibited. 6 Fluoride may also interfere with enzyme action by forming metalion complexes and in this way affect enzymes such as D.N.A. polymerase, ${ }^{7}$ though this occurs only at much higher concentrations than is found overall in fluorotic bone. When large doses have been given to animals they showed osteomalacia and compensatory hyperparathyroidism, reflected in striking changes in the parathyroid glands. ${ }^{8}$ These effects explain how the exchangeable pool and the rates of bone formation and resorption are raised in skeletal fluorosis ${ }^{9}$ - effects not found when administration was limited to three weeks. ${ }^{10}$ In this context calcium intake is of great importance; since if it is kept high and possibly enhanced by administration of vitamin $\mathrm{D}$ the balance is tipped in the direction of bone formation, and animal studies show an increase in bone ash. ${ }^{11} 12$ Indeed, if the calcium intake is increased in growing animals the osteomalacic aspects of acute fluoride administration can be completely prevented. ${ }^{13}$ These findings may explain conflicting reports of the effects of fluoride intake on the prevalence of osteoporosis in areas of varying fluoride content in the water. In Texas ${ }^{14}$ and North Dakota $^{15}$ there was less osteoporotic bone disease in high fluoridinated areas while in New York ${ }^{16}$ and Sweden ${ }^{17}$ no such relationship was noted.

So, because of the encouraging skeletal sclerosis produced in patients with myelomatosis treated with fluoride and calcium supplements ${ }^{18}$ attention has been focused on inducing similar changes in osteoporosis. Histological and microradiographic studies have shown increased thickness in bony trabeculae ${ }^{19}$ in both ribs and iliac crests. On the basis of these changes several groups reporting at a meeting in Switzerland last year $^{20}$ concluded that new bone formation could be frequently found in osteoporotic patients treated by fluoride and that it must now be accepted as a therapeutic procedure. The quality of the "new bone" formed under such conditions is, however, still in doubt, especially if adjuvant calcium, vitamin D, or androgen therapy is not given as well. ${ }^{21}$ Experiments on animals have shown that simple administration of fluoride makes the bone more flexible but that its load bearing qualities are impaired ${ }^{22}$ and its breaking stress is significantly reduced. ${ }^{8}$

How, then, having induced the formation of, albeit rather poor quality, new bone by the use of fluoride, can the gain in matrix and cellularity be consolidated? One area of intense study is the relationship between the bone marrow and the bone-forming elements, since there is evidence of fatty infiltration of the marrow in osteoporosis. ${ }^{23}$ Once again the osteoporosis of myeloma may provide some indication that a combination of androgens and fluoride may induce hypertrophy of the marrow on the one hand and new bone formation on the other. ${ }^{24}$ Against the possible advantages of long-term fluoride therapy on the bone must be set its effects on other organs, such as gut irritation, adrenal hypertrophy, possible effects on the optic fundus, and the depression of colagen synthesis. ${ }^{25}$ The appeal of using a potentially toxic substance in the treatment of a disease of unknown aetiology must be tempered by rigorous long-term assessment of its effects on bone and other organs.

1 Posner, A. S., Eanes, E. D., Harper, R. A., and Zipkin, I., Archives of Oral Biology, 1963, 8, 549 .

2 Young, R. A., Van Der Lugt, W., and Elliott, J. C., Nature, 1969, 223, 729.

Goldhaber, P., Israel fournal of Medical Sciences, 1967, 3, 617.

4 Peters, R. A., Shorthouse, M., and Ward, P. F. V., Proceedings of the Nutrition Society, 1969, 28, 46A.

- Hac, L. R., and Freeman, S., American Fournal of Physiology, 1967, 212, 213.

- Hac, L. R., and Freeman, S., American fournal of Physiology, 1969, 216, 179.

'Hellung-Larsen, P., and Klenow, H., Biochimica et Biophysica Acta, 1969, 190, 434.

- Faccini, J. M., Calcified Tissue Research, 1969, 3, 1.

- Rao, B. S. N., Siddiqui, A. H., and Srikantia, S. G., Metabolism, 1968, $17,366$.

10 Lukert, B. P., Bolinger, R. E., and Meek, J. C., Fournal of Clinical Endocrinology and Metabolism, 1967, 27, 828 .

11 Hauck, H. M., Steenbock, H., and Parsons, H. T., American fournal of Physiology, 1933, 103, 480.

12 Lawrenz, M., and Mitchell, H. H., Fournal of Nutrition, 1941, 22, 91.

13 Burkhart, J. M., and Jowsey, J., Fournal of Laboratory and Clinical Medicine, 1968, 72, 943.

14 Leone, N. C., Stevenson, C. A., Hilbish, T. F., and Sosman, M. C., American Fournal of Roentgenology, Radium Therapy and Nuclear Medicine, 1955, 74, 874.

16 Bernstein, D. S., Sadowsky, N., Hegsted, D. M., Guri, C. D., and Stare, F. J., Fournal of the American Medical Association, 1966, 198, 499.

16 Korns, R. F., Public Health Reports, 1969, 84, 815.

17 Alffram, P. A., Herbborg, J., and Nilsson, B. E. R., Acta Orthopaedica Scandinavica, 1969, 40, 137.

18 Cohen, P., Nichols, G. L., jun., and Banks, H. H., Clinical Orthopaedics and Related Research, 1969, 64, 221.

10 Jowsey, J., and Kelley, P. J., Proceedings of the Mayo Clinic, 1968, 43, 435.

20 Kuhlencordt, F., Kruse, H. P., Lozano-Tonkin, C., and Eckermeier, L., In Fluoride in Medicine, ed. Thomas L. Vischer, p. 169. Benn, Huber, 1970

21 Adams, P. H., and Jowsey, J., Annals of Internal Medicine, 1965, 63, 1151.

2 Beary, D. F., Anatomical Record, 1969, 164, 305.

23 Meunier, P., Aaron, J., Edouard, C., and Vignon, G., Presse Médicael, 1970, 78, 531.

24 Cohen, P., and Gardner, F. H., New England fournal of Medicine, 1964, 271, 1129.

25 Hodge, H. C., and Smith, F. A., Annual Review of Pharmacology, 1968, 8, 395. 